\title{
Comparison of Upper Extremity Isokinetic Muscle Strength of Wheelchair Basketball and Wheelchair Table Tennis Players
}

\section{Tekerlekli Sandalye Basketbol ve Tekerlekli Sandalye Masa Tenisi Sporcularının Üst Ekstremite İzokinetik Kas Kuvvetinin Karşılaştırılması}

\author{
Bihter Akınoğlu1, Tuğba Kocahan², Ahmet Buğra Selvi ${ }^{1}$ \\ ${ }^{1}$ Department of Physiotherapy and Rehabilitation, Faculty of Health Sciences, Yildirnm Beyazıt University, Ankara, \\ Turkey \\ ${ }^{2}$ Directorate of Health Affairs, General Directorate of Sports, Ministry of Youth and Sports, Ankara, Turkey
}

B. Akınoğlu it

0000-0001-5968-2948

\section{T. Kocahan \\ 0000-0001-6379-669X}

\section{A. B. Selvi \\ 0000-0002-4437-1976}

Geliş Tarihi/ Date Received: 05.04.2018

Kabul Tarihi/ Date Accepted: 08.06.2018

Yayın Tarihi/Published Online: 24.09.2018

\section{Yazışma Adresi /}

Corresponding Author:

Bihter Akınoğlu

Yıldırım Beyazıt Üniversitesi, Sağlık Bilimleri Fakültesi, Fizyoterapi ve Rehabilitasyon Bölümü, Ankara, Türkiye

E-mail: rgkardelen@yahoo.com

(C)2018 Türkiye Spor Hekimleri Derneği. Tüm hakları saklıdır.

\section{ABSTRACT}

Objectives: To compare the isokinetic muscle strength of shoulder internal rotation (IR) and external rotation (ER) muscles in wheelchair (WC) basketball and WC table tennis players. The hypothesis of our study is that the upper limbs of WC basketball players who use the WC more actively during competitions and training would be stronger.

Materials and Methods: The study was carried out by measuring the isokinetic muscle strength of shoulder IR and ER muscles of $12 \mathrm{WC}$ basketball and nine WC table tennis players with a median age of 24 years. Isokinetic muscle strength measurement was performed concentrically in the scapular neutral position with an IsoMed $2000 \AA$ device. Data analysis was made using the SPSS 20.0 package program. Median and minimum-maximum values were given as descriptive statistics; Mann Whitney-U test was used to determine differences between groups.

Results: It was determined that WC basketball and WC table tennis players have similar isokinetic muscle strengths of shoulder IR and ER muscles. There were no statistically significant differences between peak torque, peak torque / body weight, peak torque angle, muscle strength ratios, and dominant-non-dominant side strength ratios, at both $60 \%$ and $180 \%$ s angular velocities ( $p>0.05$ ).

Conclusion: It has been determined that using the WC more actively during competitions and training in WC basketball players does not appear to increase shoulder IR and ER muscle strength, comparing with WC table tennis players.

Keywords: Wheelchair, muscle strength, basketball, tennis

öz

Amaç: Tekerlekli sandalye (TS) basketbol ve TS masa tenisi sporcularında omuz internal rotasyon (IR) ve eksternal rotasyon (ER) kaslarının izokinetik kas kuvvetinin karşılaştııımasıdır. Çalışmanın ana hipotezi, müsabaka ve antrenmanlar sırasında TS'yi daha aktif olarak kullanan TS basketbol sporcularının üst ekstremitelerinin daha kuvvetli olacağıdır.

Gereç ve Yöntemler: Çalışma; yaş ortancaları 24 yıl olan 12 TS basketbol ve dokuz TS masa tenisi sporcusunun omuz IR ve ER kaslarının izokinetik kas kuvvet ölçümü ile gerçekleştirildi. İzokinetik kas kuvvet ölçümü IsoMed $2000^{\circledR}$ cihazı ile skapular nötral pozisyonda konsantrik-konsantrik olarak gerçekleştirildi. Verilerin analizi SPSS 20.0 paket programı kullanılarak yapıldı. Tanımlayıcı istatistikler olarak ortanca değer ile 
minimum maksimum değerler verildi; gruplar arasındaki farklılıkları belirlemek için Mann Whitney-U testi uygulandı. Bulgular: TS basketbol ve TS masa tenisi sporcularının omuz IR ve ER kaslarının $60 \%$ se $180 \%$ açısal hızlardaki izokinetik kas kuvvetlerinin birbirine benzer olduğu saptandı. Elde edilen zirve kuvvet, zirve kuvvet / vücut ağılığı, zirve kuvvetteki açı değerleri ile kas kuvvet oranları ve dominant-dominant olmayan taraf kuvvet oranları arasında istatistiksel olarak anlamlı farklılık olmadığı belirlendi $(p>0.05)$.

Sonuç: TS basketbol sporcularının TS'yi müsabaka ve antrenmanlar sırasında daha aktif kullanıyor olmalarına karşın, omuz IR ve ER kas kuvvetlerinin TS masa tenisi sporcularına göre daha yüksek olmadığı belirlendi.

Anahtar Sözcükler: Tekerlekli sandalye, kas kuvveti, basketbol, tenis

Available at: http://journalofsportsmedicine.org and http://dx.doi.org/10.5152/tjsm.2018.105

Cite this article as: Akinoglu $B$, Kocahan $T$, Selvi AB. Comparison of upper extremity isokinetic muscle strength of wheelchair basketball and wheelchair table tennis players. Turk J Sports Med. 2018;53(4):160-66.

\section{GíRis}

Tekerlekli sandalye (TS) basketbol sporu, paralimpik sporlar arasında en popüler olanıdır (1). TS basketbol sporu özellikle tekerleği çevirme, ribaund alma, pas atma, baş üstü seviyede şut atma gibi manevralar ve yüksek yoğunluktaki aktivitelerle karakterize, kural ve sinıflandırmalar çerçevesinde oynanan bir spordur $(2,3)$. TS ile mobilize olan bireylerde üst ekstremite kas kuvveti oldukça önemlidir (4). TS basketbol sporunda sporcuların üst ekstremite kas kuvveti, endürans, sürat ve el becerisi gibi parametreler; hem basket atma, pas atma, firlatma ve TS'nin itilmesi gibi spora özgü aktiviteleri yerine getirmede, hem de TS'yi kontrol etmede kritik önem arz eder $(5,6)$.

TS masa tenisi ise paralimpik oyunlar kapsamında yer alan ve en çok tercih edilen spor dallarından biridir $(7,8)$. TS masa tenisinde teknik, oyuncuya göre değişse de, genel olarak temel terimler ve biyomekaniği aynıdır. Müsabaka esnasında topun karşıllklı gidip gelmesi söz konusudur. Tıpkı TS basketbol sporunda olduğu gibi TS masa tenisi sporunda da topu karşılama sırasında yapılan kısa vuruș, uzun vuruș ve düz vuruşlarda üst ekstremite kas kuvveti oldukça önemli bir parametredir $(7,8)$.

TS kullanımı, üst ekstremite kaslarının ve özellikle omuz kuşağı kaslarının aktif ve koordineli olarak kullanılmasını gerektirir (9). Omuz kuşağı kaslarının zayıf olmasının, omuz ağrısı ve "impingement" sendromu ile ilişkili olduğu ve omuz kuşağı kasları arasındaki kuvvetsizlik ve kuvvet dengesizliğinin de omuz ağrısı ile ilişkili olabileceği ve bunun spor başarısını etkileyebileceği belirtilmektedir (8-11).

Bu çalışma ile TS'nin daha aktif kullanımının kas kuvvetini nasıl etkilediği hakkında fikir edinmek ve bu iki spor branșının özellikleri konusunda literatüre katkı sağlayarak TS kullanan bireylere öneriler verebilmek amaçlandı.

\section{GEREÇ ve YÖNTEMLER}

Araştırmanın örneklem grubunu, 12 TS basketbol ve dokuz TS masa tenisi olmak üzere toplam 21 TS sporcusu oluşturdu. Katılımcllar ulusal ve/veya uluslarası düzeyde müsabakalara katılmış ve en az üç yıldır bu sporu yapan sporculardan seçildi. TS sporcusunun üç yıldan daha kısa süredir spor yapıyor olması, son altı ay içerisinde üst ekstremitesiyle ilgili bir spor yaralanması veya ortopedik bir işlem geçirmiş olması, üst ekstremitesinde normal eklem hareket açıklığında kısıtlılık ve üst ekstremitesinde devam eden ağrısının olması çalışmadan dışlama kriterleri olarak belirlendi. Başlangıçta çalışmaya dâhil edilen 14 TS basketbol ile 11 TS masa tenisi sporcusundan dördü dişlama kriterler var olduğu için çalışma dışı bırakıldı (ikişer sporcu). Çalışmaya katılan sporculara çalışma hakkında bilgi verildi, çalışmaya katılmayı kabul eden tüm sporculardan imzalı onamları alındı. Ayrıca çalışmanın yapılabilmesi için Ankara Yıldırım Beyazıt Üniversitesi Sosyal ve Beşeri Bilimler etik kurulundan gerekli izin alındı. Sporcuların doğum tarihi, boy ve vücut ağırlığı bilgileri 
kaydedildikten sonra üst ekstremite izokinetik kas kuvvetleri değerlendirildi.

Katılımcıların vücut ağırlığı, dijital TS tartısı kullanılarak ölçüldü ve değer $\mathrm{kg}$ cinsinden kaydedildi. Daha sonra TS boş olacak şekilde tekrar ölçüldü ve bu değer ilk ölçülen değerden çıkarılarak sporcuların net ağırlıkları kaydedildi. Sporcuların boy uzunluğu ve kulaç uzunluğu kaydedildi (12). Sporcuların ayağa kalkamaması nedeniyle boy uzunlukları sözel olarak öğrenildi. Kulaç uzunluğunu ölçmek için, sporcular TS'de oturur pozisyonda sirtları bir duvara dönük olarak, dirsekler düz, omuzlar $90^{\circ}$ abdüksiyonda olacak şekilde kollarını iki yana açmaları istendi. Sporcuların orta parmaklarının geldiği noktalar duvar üzerinde işaretlenerek aradaki mesafe ölçüldü. Ayrıca sporcuların spor yaptığı yıl süresi, sinıflama puanları, dominant tarafları ve engel durumları kendilerine sorularak kaydedildi.

Sporcuların yaş, vücut ağırlığl, boy uzunluğu, kulaç uzunluğu, vücut kütle indeksleri, spor yaptıkları süre, sınıflama puanları, dominant taraf bilgileri ve engel durumları Tablo 1 ve Tablo 2'de gösterilmektedir.

Sporcuların omuz IR ve ER kaslarının kuvveti $60^{\circ} / \mathrm{s}$ ve $180^{\circ} / \mathrm{s}$ açısal hızlarda konsantrikkonsantrik olacak şekilde, skapular nötral pozisyonda $0-90^{\circ}$ açıları arasında IsoMed $2000^{\circledR}$ izokinetik dinamometre (Ferstl, Germany) ile değerlendirildi. Test öncesinde sporcuların $10 \mathrm{dk}$ boyunca TS'lerini sürerek ısınmaları sağlandı. Testler oturma pozisyonunda uyguland. Sporcular cihazın stabilizasyon bantları ile bel ve torakal bölge üzerinden stabilize edildi. Pivot nokta olekranon olacak șekilde ayarlandı. Testlerden önce sporcuların testleri anlayabilmeleri ve testlere adapte olabilmeleri için birkaç deneme yaptırıldı. Testler sırasında sporculara sözlü olarak cesaretlendirildi (13). Değerlendirme sonucunda; omuz IR ve ER kasları için $60^{\circ} / \mathrm{s}$ ve $180^{\circ} / \mathrm{s}$ açısal hızlarda ayrı ayrı zirve kuvvet (PT), PT/kg, PT'u ortaya çıkardıkları açısal değerler ile kas kuvvet oranları ve dominantdominant olmayan taraf kuvvet oranları kaydedildi $(13,14)$.

Test protokolü, skapular nötral pozisyonda $60^{\circ} / \mathrm{s}$ açısal hızda beş tekrar ve $180^{\circ} / \mathrm{s}$ açısal hızda 15 tekrar şeklinde uygulandı. İlk önce dominant taraf, sporcular dinlendiklerini ifade ettikten sonra dominant olmayan taraf test edildi (13).

İstatistiksel Analiz: Katılımcların tüm verileri "SPSS for Windows Release 20.0" (Statistical Package for Social Sciences Inc., Chicago, IL, USA) istatistiksel paket programı aracılığı ile analiz edildi. Değişkenlerin tanımlayıcı istatistikleri belirlendi. Veri sayısı az olduğundan ve normal dağılım göstermediğinden, sporcuların kas kuvvetinin karşılaştırılmasında "Mann-Whitney U” testi kullanıldı. Değişkenlerin ortancaları ile minimum ve maksimum değerleri (min-maks) kullanıldı. Verilerin analizinde istatistiksel anlamlılık değeri $\mathrm{p}<0.05$ olarak alındı.

Tablo 1. Sporcuların fiziksel özellikleri, spor yaptıkları süre, sınıflama puanları ve dominant taraf bilgileri

\begin{tabular}{lccc}
\hline & $\begin{array}{c}\text { TS Basketbol } \\
\text { (n=12) }\end{array}$ & $\begin{array}{c}\text { TS Masa tenisi } \\
\text { (n=9) }\end{array}$ & p \\
\hline Yaş (yıl) & $24(16-45)$ & $24(16-42)$ & 0.731 \\
\hline Vücut ağırlığı (kg) & $65(47-105)$ & $62(43-75)$ & 0.512 \\
Boy uzunluğu (m) & $1.78(1.45-1.94)$ & $1.60(1.15-1.175)$ & 0.361 \\
\hline Kulaç uzunluğu (m) & $1.82(1.52-1.90)$ & $1.68(1.38-1.80)$ & 0.286 \\
VKİ $\left(\mathrm{kg} / \mathrm{m}^{2}\right)$ & $22.2(15.6-45.6)$ & $22.5(16.8-45.4)$ & 0.970 \\
Spor yaptığı süre (yıl) & $5(3-18)$ & $7(3-17)$ & 0.672 \\
Sinıflama puanı & $3.0(1.5-4.0)$ & $4.0(2.0-5.0)$ & 0.331 \\
Dominant taraf & Sağ: $8(\% 66)$, sol: $4(\% 33)$ & Sağ: $7(\% 78)$, sol: $2(\% 22)$ & \\
\hline
\end{tabular}

Değerler ortanca (min-maks olarak); VKİ: Vücut kütle indeksi 
Tablo 2. Sporcuların engel durumları

\begin{tabular}{lcc}
\hline Engel durumu & $\begin{array}{c}\text { TS Basketbol } \\
(\mathbf{n = 1 2})\end{array}$ & $\begin{array}{c}\text { TS Masa tenisi } \\
(\mathbf{n = 9})\end{array}$ \\
\hline Ampütasyon & 4 & 2 \\
\hline Spina bifida & 2 & 2 \\
\hline Paraparezi & 2 & 1 \\
\hline Parapleji & 1 & 1 \\
\hline Alt ekstremite eklem problemleri & 2 & - \\
\hline Müsküler distrofi & - & 2 \\
\hline Polio sekeli & 1 & 1 \\
\hline
\end{tabular}

Tablo 3. Sporcuların $60^{\circ} / \mathrm{s}$ açısal hızdaki izokinetik kas kuvvetinin karşılaştırılması

\begin{tabular}{|c|c|c|c|c|c|}
\hline & & & $\begin{array}{c}\text { TS Basketbol } \\
(n=12)\end{array}$ & $\begin{array}{l}\text { TS Masa tenisi } \\
\qquad(n=9)\end{array}$ & $\mathbf{p}$ \\
\hline \multirow{7}{*}{ DM } & \multirow{3}{*}{ IR } & PT & $48.9(35.8-74.8)$ & 47.8 (23.8-95.4) & 0.909 \\
\hline & & PT/W & $0.77(0.55-1.10)$ & $0.80(0.52-1.32)$ & 0.732 \\
\hline & & $\operatorname{Açı}\left({ }^{\circ}\right)$ & $43(19-67)$ & $45(33-49)$ & 0.849 \\
\hline & \multirow{3}{*}{ ER } & PT & $31.3(22.3-48.6)$ & $23.4(17.8-54.9)$ & 0.261 \\
\hline & & $\mathrm{PT} / \mathrm{W}$ & $0.48(0.39-0.75)$ & $0.52(0.33-0.70)$ & 0.824 \\
\hline & & $\operatorname{Açı}\left({ }^{\circ}\right)$ & $70(44-78)$ & $70(54-77)$ & 0.941 \\
\hline & IR/ER & $\%$ & $65.6(44.4-79.2)$ & $57.55(41.1-78.2)$ & 0.95 \\
\hline \multirow{7}{*}{ NDM } & \multirow{3}{*}{ IR } & PT & $45.9(24.9-93.6)$ & $40.6(24.9-88.6)$ & 0.789 \\
\hline & & PT/W & $0.71(0.32-1.14)$ & $0.80(0.53-1.23)$ & 0.909 \\
\hline & & Açı $\left({ }^{\circ}\right)$ & $49(30-85)$ & $43(31-65)$ & 0.593 \\
\hline & \multirow{3}{*}{ ER } & PT & $27.1(18.1-51.1)$ & $21.9(14.1-50.8)$ & 0.201 \\
\hline & & $\mathrm{PT} / \mathrm{W}$ & $0.44(0.28-0.64)$ & $0.44(0.31-0.61)$ & 1.000 \\
\hline & & Açı $\left({ }^{\circ}\right)$ & $70(44-78)$ & $71(44-77)$ & 0.824 \\
\hline & IR/ER & $\%$ & $93.5(62.4-176.2)$ & $75.5(48.6-175.2)$ & 0.201 \\
\hline \multicolumn{2}{|c|}{ DM PT/NDM PT (IR) } & $\%$ & $103.3(80.0-177.1)$ & $112.7(95.8-137.4)$ & 0.790 \\
\hline \multicolumn{2}{|c|}{ DM PT/NDM PT (ER) } & $\%$ & 111.7 (91.7-152.7) & $113.8(102.1-134.6)$ & 0.824 \\
\hline
\end{tabular}

Değerler ortanca (min-maks olarak); DM: dominant taraf; NDM: dominant olmayan taraf; PT: zirve tork; RT/W: zirve tork/kg; IR: internal rotasyon; ER: eksternal rotasyon 
Tablo 4. Sporcuların $180^{\circ}$ /s açısal hızdaki izokinetik kas kuvvetinin karşılaştırılması

\begin{tabular}{|c|c|c|c|c|c|}
\hline & & & $\begin{array}{c}\text { TS Basketbol } \\
(n=12)\end{array}$ & $\begin{array}{l}\text { TS Masa Tenisi } \\
\qquad(n=9)\end{array}$ & $\mathbf{p}$ \\
\hline \multirow{7}{*}{ DM } & \multirow{3}{*}{ IR } & PT & $44.8(31.3-55.6)$ & $42.9(23.4-74.1)$ & 0.370 \\
\hline & & PT/W & $0.65(0.46-0.98)$ & $0.78(0.51-1.03)$ & 0.201 \\
\hline & & $\operatorname{Açı~}\left({ }^{\circ}\right)$ & $22(20-70)$ & $24(18-59)$ & 0.503 \\
\hline & \multirow{3}{*}{ ER } & PT & $31.3(22.3-48.6)$ & $23.4(17.8-54.9)$ & 0.412 \\
\hline & & PT /W & $0.48(0.39-0.75)$ & $0.52(0.33-0.74)$ & 1.000 \\
\hline & & $\operatorname{Açı}\left({ }^{\circ}\right)$ & $65(58-70)$ & $61(49-72)$ & 0.370 \\
\hline & IR/ER & $\%$ & $70.0(36.9-86.3)$ & $63.4(34.3-72.4)$ & 0.175 \\
\hline \multirow{7}{*}{ NDM } & \multirow{3}{*}{ IR } & PT & $38.8(16.6-65.1)$ & $36.1(21.1-69.6)$ & 0.800 \\
\hline & & PT/W & $0.60(0.21-0.86)$ & $0.66(0.43-0.96)$ & 0.603 \\
\hline & & $\operatorname{Açı}\left({ }^{\circ}\right)$ & $28(20-59)$ & $26(20-41)$ & 0.710 \\
\hline & \multirow{3}{*}{ ER } & PT & $24.6(12.9-41.8)$ & $20.1(11.8-46.5)$ & 0.370 \\
\hline & & PT/W & $0.42(0.21-0.61)$ & $0.36(0.26-0.65)$ & 0.824 \\
\hline & & Açı $\left({ }^{\circ}\right)$ & $66(58-79)$ & $60(39-72)$ & 0.080 \\
\hline & IR/ER & $\%$ & $64.8(30.3-100.0)$ & $55.7(36.0-86.6)$ & 0.370 \\
\hline \multicolumn{2}{|c|}{ DM PT/NDM PT(IR) } & $\%$ & $110.6(75.0-175.3)$ & $116.4(93.1-143.5)$ & 0.503 \\
\hline \multicolumn{2}{|c|}{ DM PT/NDM PT(ER) } & $\%$ & $102.2(83.8-189.0)$ & $115.2(100.0-156.0)$ & 0.503 \\
\hline
\end{tabular}

Değerler ortanca (min-maks olarak); DM: dominant taraf; NDM: dominant olmayan taraf; PT: zirve tork; RT/W: zirve tork/kg; IR: internal rotasyon; ER: eksternal rotasyon

\section{BULGULAR}

Çalışmada iki grup arasında yaş, vücut ağırlığı, boy uzunluğu, kulaç uzunluğu, vücut kütle indeksi, spor yaptıkları süre ve sınıflama puanları arasında istatistiksel olarak fark olmadığı belirlendi ( $p>0.05$ ) (Tablo 1 ve Tablo 2).

İki grubun omuz IR ve ER kaslarının $60^{\circ} / \mathrm{s}$ ve $180^{\circ} / \mathrm{s}$ açısal hızlardaki izokinetik kas kuvvet ölçümü sonucunda elde edilen PT, PT/kg, PT'yi ortaya çıkardıkları açısal değerler ile kas kuvvet oranları ve dominant-dominant olmayan taraf kas kuvvet oranları arasında istatistiksel olarak anlamlı farklılık olmadığı belirlendi ( $p>0.05)$.
Her iki grubun IR/ER kas kuvvet oranları ve dominant/dominant olmayan taraf kas kuvvet oranları incelendiğinde; IR kas kuvvetinin ER kas kuvvetine göre ve dominant tarafın dominant olmayan tarafa göre daha kuvvetli olduğu saptandı (Tablo 3 ve Tablo 4).

\section{TARTIŞMA}

TS basketbol ve masa tenisi sporcularının omuz IR ve ER kaslarının izokinetik kas kuvvetlerinin karşılaştırıldığı çalışma sonucunda; iki grubun omuz IR ve ER kas kuvvetlerinin, kas kuvvet 
oranlarının ve dominant ekstremiteleri ile dominant olmayan ekstremitelerinin kuvvet farklarının birbirine benzer olduğunu belirledik.

TS basketbol ve TS masa tenisi sporcularında kas kuvveti performansın önemli belirleyicisidir $(8,15)$. TS basketbol sporu daha çok baş üzeri üst ekstremite aktivitelerini içerir. Literatürde baş üzeri ve baş üzeri olmayan branşlarda performans gösteren TS sporcularının skapular diskinezilerinin araştırıldığı bir derlemede; baş üzeri spor yapan sporcularda skapular diskinezinin daha fazla olduğu belirtilmiştir (16) Biz de bu nedenle çalışmada bu faktörden kaynaklanabilecek riski en aza indirebilmek ve ölçümler sırasında meydana gelebilecek olası omuz yaralanmalarından kaçınmak amacıyla skapular nötral pozisyonu tercih ettik.

Ampüte futbol. TS basketbol ve TS masa tenisi sporcularının skapular dinlenme pozisyonları ve fonksiyonlarını karşılaștırmak amacıyla yapılan bir çalışmada; ampüte futbol ile her iki TS sporcuları arasında fark bulunurken; TS basketbol ile TS masa tenisi sporcuları arasında fark olmadığını belirlenmiștir (17). Bu bağlamda çalıșmamızda karșılaștırılan grupların skapular dinlenme pozisyonları ve fonksiyonları ile demografik özelliklerinin birbirlerine benzer olması, çalışma sonuçlarının diş etkenlerden çok fazla etkilenmeyeceği şeklinde yorumlanabilir.

Literatürde TS basketbol ile TS masa tenisi sporcularının kas kuvvetini karşılaştıran herhangi bir çalıșma bulunamadı. Ancak TS basketbol ile TS masa tenisi sporcularının fizyolojik gereksinimin belirlenip karșılaștırıldığı bir çalışmada TS basketbol sporcularının yaptıkları sporun doğası gereği daha yüksek yoğunluklu egzersiz programlarına ihtiyaçları olduğu belirlenmiştir (18). TS basketbol sporcularının yüksek yoğunluklu egzersiz programları kas kuvvetlerinin fazla olmasını sağlar. Ancak çalıșmamız sonucunda iki grubun omuz IR ve ER kaslarının kas kuvveti. kas kuvvet oranları ve dominant-dominant olmayan taraf kuvvet oranları birbirine benzer bulundu.

Omuz IR/ER kas kuvvet oranı ile ilgili yapılan çalışmalar incelendiğinde, bu oranın \%75-\%100 arasında olmasının omuz stabilitesi için gerekli olduğu belirtilmektedir $(14,19)$. Çalışmamız sonucunda bu oranın iki grupta da her iki açısal hız için ortalama \%50-70 arasında olduğu ve ER kaslarının aleyhinde bir dengesizlik olduğunu ve aynı zamanda dominant tarafin dominant olmayan tarafa göre daha kuvvetli olduğunu belirledik. Sonuçlarımıza benzer olarak Bernard ve ark. yaptıkları çalışmada TS basketbol ve TS masa tenisi sporcuları ile TS kullanan sedanter bireylerin IR kaslarının ER kaslarına göre daha kuvvetli olduğu ve dominant tarafın dominant olmayan taraftan daha kuvvetli olduğunu belirlemişerdir (19).

Çalışmamızın sınırlılıkları; sadece iki TS spor branșının dâhil edilmesi ve sadece omuz eklemi IR ve ER kas kuvvetinin konsantrik olarak değerlendirilmiş olmasıdır. Daha farklı spor branşları ile daha fazla eklemi ve değerlendirme yöntemini içeren ve kontrol grubu ile karşılaştırma yapan çalışmalar gereklidir.

Sonuç olarak; çalışmamızda ulusal ve uluslararası düzeyde spor yapan TS basketbol ile TS masa tenisi sporcularının omuz IR ve ER izokinetik kas kuvvetlerinin birbirlerine benzer olduğu; ancak her iki spor branşında da IR kaslarının ER kaslarına göre ve dominant tarafın dominant olmayan tarafa göre daha kuvvetli olduğu belirlendi. Çalışmamı sonucunda TS sporcularinda dominant olmayan taraf omuz kaslarının ve her iki taraf omuzun ER kaslarının kuvvetlendirilmesini önermekteyiz.

\section{KAYNAKLAR}

1. Gil-Agudo A, Del Ama-Espinosa A, Crespo-Ruiz B. Wheelchair basketball quantification. Phys Med Rehabil Clin N Am. 2010;21(1):141-56.

2. McInnes SE, Carlson JS, Jones CJ, et al. The physiological load imposed on basketball players during competition. J Sports Sci. 1995;13(5):387-97.

3. Molik B, Laskin JJ, Kosmol A, et al. Relationship between functional classification levels and anaerobic performance of wheelchair basketball athletes. Res $Q$ Exerc Sport. 2010;81(1):69-73.

4. Van Der Woude LH, Croonenborg JJ, Wolff I, et al. Physical work capacity after 7 week of wheelchair training: effect of intensity in able-bodied subjects. Med Sci Sports Exerc. 1999;31(2):331-41.

5. Rankin JW, Richter WM, Neptune RR. Individual muscle contributions to push and recovery subtasks during wheelchair propulsion. J Biomech. 2011;44(7): 1246-52. 
6. Bayramlar K, Ergun N. Engelli masa tenisi oyuncularında yaşam kalitesinin değerlendirilmesi. Turkiye Klinikleri J Sports Sci. 2009;1(1):53-7.

7. Kondrič M, Zagatto AM, Sekulić D. The physiological demands of table tennis: a review. J Sports Sci Med. 2013;12(3):362-70.

8. Moon HB, Park SJ, Kim AC, et al. Characteristics of upper limb muscular strength in male wheelchair tennis players. J Exerc Rehabil. 2013;9(3):375-80.

9. Heyward OW, Vegter RJK, de Groot S, et al. Shoulder complaints in wheelchair athletes: A systematic review. PLoS One, 2017 Nov 21;12(11):e0188410.

10. Miyahara M, Sleivert GG, Gerrard DF. The relationship of strength and muscle balance to shoulder pain and impingement syndrome in elite quadriplegic wheelchair rugby players. Int J Sports Med. 1998;19(3): 210-4.

11. Burnham RS, May L, Nelson E, et al. Shoulder pain in wheelchair athletes. The role of muscle imbalance. Am J Sports Med, 1993;21(2):238-42.

12. Lohman TG, Roche AF, Martorel R. Anthropometric Standardization Manual. Champaign: Human Kinetics, 1988.
13. Akınoğlu B, Kocahan T. Characteristics of upper extremity's muscle strength in Turkish national wheelchair basketball players team. J Exerc Rehabil. 2017;13(1):62-7.

14. Berckmans K, Maenhout AG, Matthijs L, et al. The isokinetic rotator cuff strength ratios in overhead athletes: Assessment and exercise effect. Phys Ther Sport. 2017 Sep;27:65-75.

15. Granados C, Yanci J, Badiola A, et al. Anthropometry and performance in wheelchair basketball, J Strength Cond Res. 2015;29(7):1812-20.

16. Burn MB, McCulloch PC, Lintner DM, et al. Prevalence of scapular dyskinesis in overhead and nonoverhead athletes: a systematic review. Orthop J Sports Med. 2016 Feb 17;4(2):2325967115627608.

17. Aytar A, Zeybek A, Pekyavas NO, et al. Scapular resting position, shoulder pain and function in disabled athletes. Prosthet Orthot Int. 2015;39(5):390-6.

18. Croft L, Dybrus S, Lenton J, et al. A comparison of the physiological demands of wheelchair basketball and wheelchair tennis. Int J Sports Physiol Perform. 2010; 5(3):301-15.

19. Bernard PL, Codine P, Minier J. Isokinetic shoulder rotator muscles in wheelchair athletes. Spinal Cord. 2004;42(4):222-9. 